\title{
Crescimento inicial de milho e sua relação com o rendimento de grãos
}

\author{
Initial growth of maize hybrids and its relation with grain yield
}

\author{
Milton Luiz de Almeida ${ }^{1}$ Luís Sangoi ${ }^{2}$ Itamar Cristiano Nava $^{3}$ \\ Jonantam Galio ${ }^{3}$ Paulo Sérgio Trentin ${ }^{3}$ Clair Rampazzo ${ }^{3}$
}

\section{RESUMO}

Este trabalho foi conduzido objetivando identificar características morfo-fisiológicas de milho que se correlacionam com seu crescimento inicial, para determinar sua importância no rendimento de grãos. $O$ experimento foi conduzido no município de Lages, SC, nos anos agrícolas de 1998/99 e 1999/00. Em 1998/99 avaliaram-se os hibridos C901, AS 3601, C 505, AS 3466 e AS 32 e em 1999/00 os hibridos C909, AS 3601, DINA 500, AS 3466 e AS 32. Utilizou-se o delineamento de blocos ao acaso, com quatro repetições. O crescimento inicial foi avaliado através de seis coletas semanais, da emergência até o estádio de dez folhas expandidas. Em cada coleta, determinou-se a área foliar, índice de área foliar (IAF), acúmulo de massa seca, taxa de crescimento celular (TCC) e taxa de expansão celular (TEC). O híbrido AS 3601 apresentou maior área foliar, IAF e TEC do que os demais híbridos em 1998/99. No segundo ano agrícola, o hibrido AS 3466 destacou-se dos demais em acúmulo de massa seca e TCC. Não foram registradas diferenças significativas no rendimento de grãos dos híbridos testados nas duas estações de crescimento. Houve baixa correlação entre os parâmetros de crescimento inicial e o rendimento de grãos da cultura do milho. Já as variáveis utilizadas para estimar o crescimento inicial (MS, área foliar, TEC, IAF e TCC) se correlacionaram positivamente.

Palavras-chave: Zea mays, vigor, radiação solar, produtividade.

\begin{abstract}
This study was conducted aiming to identify morphological and physiological traits associated with the initial growth speed and to determine the importance of a vigorous early growth to set high grain yields. The study was conducted in Lages, SC, during 1998/99 and 1999/00 growing seasons. A randomized complete block design was used. Hybrids C901, AS 3601, C 505, AS 3466 and AS 32 were avaluated in 1998/99, whereas in 1999/00 the studied hybrids were C 909, AS 3601, DINA 500, AS 3466 and AS 32. Maize initial growth was evaluated through six samplings. Samples were taken weekly from plant emergence the ten fully expanded leaves stage. Leaf area, leaf area index, dry mass accumulation, cellular growth rate (CGR) and cellular expansion rate (CER) were estimated. Hybrid AS 3601 presented larger values of leaf area, IAF and CER than the other genotypes in 1998/99. In the second growing season, Hybrid AS 3466 had the highest values for dry mass and CGR. There was no significant difference among hybrids for grain yield. Low correlation values between initial growth parameters and maize grain yield were found. Otherwise, leaf area, leaf area index, dry mass accumulation, $C G R$ and CER showed high correlation.
\end{abstract}

Key words: Zea mays, vigor, solar radiation, productivity.

'Engenheiro Agrônomo, Doutor, Professor do Departamento de Fitotecnia da Universidade do Estado de Santa Catarina (UDESC), Av. Luiz de Camões, 2090, CP 281, 88520-000, Lages, SC. E-mail: a2mla@cav.udesc.br. Autor para correspondência. Bolsista do CNPq.

${ }^{2}$ Engenheiro Agrônomo, PhD, Professor do Departamento de Fitotecnia da UDESC. Bolsista do CNPq.

${ }^{3}$ Acadêmico do Curso de Graduação em Agronomia da UDESC, Bolsista de Iniciação Científica do CNPq 


\section{INTRODUÇÃO}

Os melhoristas buscam constantemente características de planta que possam aumentar a sua capacidade produtiva. Incrementos na produtividade têm sido obtidos através de diferentes estratégias. Para algumas culturas, como o milho e a soja, os ganhos de produtividade têm sido atribuídos à maior acumulação de massa seca (MS) pela comunidade (CREGAN \& YAKLICH, 1986; TOLLENAAR, 1991; TOLLENAAR \& WU, 1999). Para outras, como o trigo e a cevada, incrementos do potencial produtivo foram alcançados pelo aumento do índice de colheita (AUSTIN et al., 1980; COX etal., 1988; BOUKERROU \& RASMUSSON, 1990).

A grande maioria das plantas de lavoura segue um modelo de crescimento sigmóide. No início do ciclo, o crescimento é lento, aumentando gradativamente até atingir um platô, quando se estabiliza. A menor taxa de crescimento inicial é verificada porque o número de células que se dividem é pequeno. Isto proporciona uma pequena área foliar e, conseqüentemente, um menor aproveitamento da radiação fotossinteticamente ativa (LOOMIS \& AMTHOR, 1999). Genótipos que direcionam maior quantidade de fotoassimilados para a produção de folhas, durante a fase inicial do crescimento, apresentam um maior crescimento inicial. Isto pode se refletir no potencial produtivo do milho, cultura que apresenta pequeno acúmulo de massa seca da emergência até o estádio de seis folhas expandidas (FANCELLI, 2000).

A taxa e duração da área foliar são variáveis importantes para caracterizar o crescimento das plantas porque determinam a quantidade de radiação solar interceptada para a fotossíntese (STEWART \& DWYER, 1994; WESTGATE et al., 1997). O maior crescimento inicial pode incrementar o aproveitamento da radiação solar disponível no início do ciclo do milho, aumentando a disponibilidade de carboidratos para a diferenciação de um maior número de espigas por planta .

O crescimento das plantas não é regulado somente pela assimilação de carbono, mas também pela partição de assimilados, sendo a regulação de ambos os processos controlada pelo genótipo e pelo ambiente (ROCHER et al., 1989). Variação genética para o crescimento inicial tem sido identificada em milho através de diferentes características, tais como taxa de aparecimento de folhas, número de folhas, área foliar, acumulação de massa seca e vigor inicial de plântulas (CAUSSE et al., 1995).

Diferenças na velocidade de crescimento inicial da cultura do milho podem ser facilmente visualizadas comparando-se plântulas de híbridos, as quais emergem mais rapidamente do que às de linhagens (ROOD et al., 1990). Essas plântulas também são mais pesadas e apresentam maior área foliar. ROCHER et al. (1989), ROOD et al. (1990) e CAUSSE et al. (1995) reforçam a hipótese de que o crescimento inicial é uma característica importante para a capacidade produtiva das plantas, estando correlacionado com algumas enzimas chaves no processo de fixação e distribuição dos fotoassimilados na planta.

Este trabalho teve por objetivo identificar características morfo-fisiológicas de planta que se correlacionam com o crescimento inicial e determinar a sua importância para a formação do rendimento de grãos de híbridos de milho.

\section{MATERIAL E MÉTODOS}

Dois experimentos foram conduzidos no município de Lages, localizado no Planalto Sul de Santa Catarina, nas estações de crescimento 1998/99 e 1999/ 00 . As coordenadas geográficas da região são $27^{\circ} 52^{\prime} 30^{\prime \prime}$ de latitude sul e $50^{\circ} 18^{\prime} 20^{\prime \prime}$ de longitude oeste. O clima é do tipo $\mathrm{Cfb}$, de acordo com a classificação de Köppen, apresentando verões brandos com chuvas bem distribuídas. O solo da área experimental é um nitossolo vermelho (EMBRAPA, 1999).

O delineamento experimental utilizado foi o de blocos completamente casualizados com quatro repetições. Os tratamentos foram constituídos por cinco híbridos de milho. Na estação de crescimento 1998/99 utilizaram-se os híbridos C 901 e AS 3601 (superprecoces) e C 505, AS 3466 e AS 32 (precoces). Já na estação de crescimento 1999/00, utilizaram-se os híbridos C 909 e AS 3601 (superprecoces) e DINA 500, AS 3466 e AS 32 (precoces).

Os experimentos foram conduzidos no sistema de semeadura direta, sobre uma cobertura morta de aveia preta. Esta foi dessecada através da aplicação de $1.400 \mathrm{~g}$ de i.a. do herbicida glifosate, 15 dias antes da semeadura do milho. Na adubação de manutenção, aplicaram-se $20 \mathrm{~kg} \mathrm{ha}^{-1}$ de N, $70 \mathrm{~kg} \mathrm{ha}^{-1} \mathrm{de}_{2} \mathrm{O}_{5}$ e $100 \mathrm{~kg}$ $\mathrm{ha}^{-1}$ de $\mathrm{K}_{2} \mathrm{O}$. Em cobertura aplicou-se mais $80 \mathrm{~kg} \mathrm{ha}^{-1} \mathrm{de}$ $\mathrm{N}$ quando as plantas apresentavam-se no estádio V5 (cinco folhas expandidas) da escala proposta por RITCHIE \& HANWAY (1993). A adubação foi feita considerando os valores de reposição sugeridos pela COMISSÃO DE FERTILIDADE DO SOLO -RS/SC (1995), para lavouras de milho com perspectivas de obtenção de rendimento de grãos superiores a $6.000 \mathrm{~kg} \mathrm{ha}^{-1}$.

Em ambos os anos, a semeadura foi realizada na primeira quinzena do mês de novembro, colocando- 
se manualmente de três a quatro sementes por cova. $\mathrm{O}$ espaçamento entre linhas utilizado foi de $0,70 \mathrm{~m}$, a fim de se obter uma densidade de 60.000plantas ha-1.

Após a semeadura aplicou-se uma combinação de atrasina $(1.400 \mathrm{~g}$ i.a. por hectare) e metolachlor $(2.100 \mathrm{~g}$ i.a. por hectare) sobre a superfície do solo para o controle pré-emergente de plantas daninhas. Sempre que necessário, efetuou-se controle mecânico pós-emergente das invasoras de forma que as mesmas não interferissem no desenvolvimento adequado da cultura. No estádio V3, três folhas totalmente expandidas (RITCHIE \& HANWAY, 1993), efetuou-se o desbaste para ajustar a população aos valores desejados.

Cada parcela foi constituída por oito linhas de 7 metros de comprimento. A área útil das mesmas, na qual o rendimento de grãos e seus componentes foram determinados, englobou as linhas de número $2 \mathrm{e}$ 3. As linhas de número 5, 6 e 7 foram utilizadas para a coleta de plantas. As variáveis de crescimento inicial foram determinadas através de seis coletas semanais que se estenderam até o estádio de dez folhas expandidas. Em cada coleta, foram amostradas 10 plantas por parcela. Na estação de crescimento 1998/ 99, a primeira coleta foi feita sete dias após a emergência. Na estação 1999/00, a primeira coleta foi realizada três dias após a emergência. Foram feitas as seguintes determinações nas plantas coletadas: número de folhas; comprimento e largura de folhas; massa seca de folhas + colmos (MS). Com base nestas avaliações, calculou-se as seguintes variáveis: área foliar por planta $(\mathrm{AF})=$ comprimento da folha $\mathrm{x}$ largura da folha $\mathrm{x}$ número de folhas $\mathrm{x} 0,75$; índice de área foliar $(\mathrm{IAF})=\mathrm{AF} /$ área de solo ocupada pelas plantas amostradas; taxa de expansão celular (TEC) = área foliar/ número de dias da emergência até a amostragem; taxa de crescimento celular $($ TCC $)=$ massa seca acumulada por planta por $\mathrm{m}^{2} /$ número do dias da emergência até a amostragem.

A colheita foi realizada, obedecendo-se as bordaduras, numa área útil de $8,4 \mathrm{~m}^{2}$, nos dias 03/05/99 e 27/04/00, respectivamente no primeiro e segundo experimento. Determinou-se o número de plantas, o número de espigas, o número de grãos, a massa de mil grãos e o rendimento de grãos ( $13 \%$ de umidade). Além dessas determinações, avaliou-se também o rendimento biológico (massa seca de toda a planta) e o índice de colheita (massa seca dos grãos/rendimento biológico x 100), no segundo ano agrícola.

Para análise do crescimento inicial utilizaramse parcelas sub-divididas, alocando-se os híbridos nas parcelas principais e as épocas de amostragem nas subparcelas. Os dados foram avaliados estatisticamente através da técnica da análise da variância. Quando alcançada significância estatística, as médias foram comparadas pelo teste de Duncan em nível de significância de 5\%. Para verificar a associação entre variáveis, foi realizada análise de correlação Pearson.

\section{RESULTADOS E DISCUSSÃO}

Os dois experimentos foram conduzidos sob diferentes condições de disponibilidade hídrica na fase inicial de crescimento da cultura. A estação de crescimento 1998/99 caracterizou-se pela influência do fenômeno climático denominado "la ninã", o qual reduziu a precipitação pluviométrica, principalmente na fase de estabelecimento da cultura. Neste sentido, no mês de novembro foram registrados apenas $44 \mathrm{~mm}$ de chuva, enquanto que a precipitação normal para o período na região é de $120 \mathrm{~mm}$. Já na estação de crescimento 1999/00, não houve períodos de déficit hídrico, em função da maior quantidade e melhor distribuição de chuvas (a precipitação total do mês de novembro foi de $105 \mathrm{~mm}$ ) e também da realização de irrigação suplementar para garantir emergência e desenvolvimento inicial uniformes das plantas.

Não foi identificada interação significativa entre cultivares e épocas de amostragem para nenhuma das variáveis utilizadas para caracterizar o crescimento inicial dos genótipos testados. Isto indica que a evolução dos parâmetros relacionados ao crescimento do milho da emergência até o estádio de 10 folhas expandidas não diferiu significativamente entre os híbridos analisados. Conseqüentemente, os valores dos parâmetros estudados serão apresentados considerando-se a média das seis amostragens realizadas.

Os parâmetros relacionados à massa seca das plantas (acúmulo de massa seca e taxa de crescimento celular) não diferiram entre si na média das amostragens realizadas em 1998/99 (Tabela 1). Em 1999/00, o híbrido AS3466 externou valores de massa seca e taxa de crescimento de cultura superiores aos do híbrido C 909.

Os resultados também variaram em função do ano de condução do trabalho para os parâmetros relacionados à área foliar. Em 1998/99, o híbrido AS 3601 expressou a maior produção de superfície fotossinteticamente ativa (Tabela 1), nas três formas pelas quais a mesma foi expressa (área foliar, índice de área foliar e taxa de expansão celular). No segundo ano agrícola em que se conduziu o trabalho, não houve diferenças significativas entre os híbridos quanto à área foliar e o IAF, na média das seis amostragens. De uma forma geral, os menores valores numéricos para os parâmetros relacionados com o crescimento inicial foram obtidos com o híbrido C 909. 
Tabela 1 - Massa seca (MS) da parte aérea (folhas + colmo), taxa de crescimento celular (TCC), área foliar, índice de área foliar (IAF) e taxa de expansão celular (TEC) de híbridos de milho, na média de seis amostragens. Faculdade de Agronomia, Lages, SC.

\begin{tabular}{|c|c|c|c|c|c|}
\hline Cultivares & $\begin{array}{c}\text { Massa seca } \\
\left(\text { g.m }{ }^{-2}\right)\end{array}$ & $\begin{array}{l}\text { TCC (MS. } \\
\left.\text { m }^{-2} \cdot \operatorname{dia}^{-1}\right)\end{array}$ & $\begin{array}{l}\text { Área foliar } \\
\left(\mathrm{cm}^{2} \text { planta }^{-1}\right)\end{array}$ & IAF & $\begin{array}{c}\text { TEC }\left(\mathrm{cm}^{2} \text {. }\right. \\
\left.\operatorname{dia}^{-1} \cdot \operatorname{planta}^{-1}\right)\end{array}$ \\
\hline \multicolumn{6}{|c|}{ Estação de Crescimento 1998/1999 } \\
\hline Cargill 901 & $48,0 \mathrm{~ns}$ & $0,79 \mathrm{~ns}$ & $460,0 \mathrm{~b}^{*}$ & $0,28 b^{*}$ & $14,1 b^{*}$ \\
\hline AS 3601 & 53,9 & 0,92 & $580,8 \mathrm{a}$ & $0,35 \mathrm{a}$ & $17,83 \mathrm{a}$ \\
\hline Cargill 505 & 48,8 & 0,82 & $479,0 \mathrm{~b}$ & $0,29 \mathrm{~b}$ & $14,90 \mathrm{~b}$ \\
\hline AS 32 & 46,1 & 0,76 & $484,3 \mathrm{~b}$ & $0,29 \mathrm{~b}$ & $14,43 \mathrm{~b}$ \\
\hline AS 3466 & 52,4 & 0,87 & $474,3 \mathrm{~b}$ & $0,28 \mathrm{~b}$ & $14,38 \mathrm{~b}$ \\
\hline \multicolumn{6}{|c|}{ Estação de Crescimento 1999/2000 } \\
\hline Cargill 909 & $152,5 b^{*}$ & $3,1 b^{*}$ & $730,4 \mathrm{~ns}$ & $0,44 \mathrm{~ns}$ & $29,4 b^{*}$ \\
\hline AS 3601 & $166,4 \mathrm{ab}$ & $3,5 \mathrm{ab}$ & 747,9 & 0,45 & $32,3 \mathrm{ab}$ \\
\hline Dina 500 & $177,1 \mathrm{ab}$ & $3,8 \mathrm{a}$ & 788,6 & 0,47 & $32,6 \mathrm{ab}$ \\
\hline AS 32 & $172,4 \mathrm{ab}$ & $3,6 \mathrm{ab}$ & 816,7 & 0,48 & $34,8 \mathrm{a}$ \\
\hline AS 3466 & $194,5 \mathrm{a}$ & $4,1 \mathrm{a}$ & 796,2 & 0,49 & 33,9 a \\
\hline
\end{tabular}

* médias não seguidas pela mesma letra na coluna diferem estatisticamente pelo teste de Duncan, a 5\% de significância de erro.

ns $=$ não significativo a $5 \%$, nas comparações na coluna
Não houve diferenças significativas entre o rendimento de grãos dos híbridos analisados nos dois anos em que se conduziu o trabalho (Tabela 2). Os valores de produtividade foram menores no primeiro do que no segundo ano experimental. Possivelmente estas diferenças decorreram dos períodos de déficit hídrico verificados no início do ciclo em 1998/99, os quais promoveram irregularidade na emergência das plantas. Segundo MEROTTO JR. et al. (1999) e TOLLENAAR \& WU (1999), a desuniformidade de estabelecimento de estande estimula a competição intraespecífica. Isto diminui a capacidade da comunidade de aproveitar os recursos disponíveis, limitando o seu potencial produtivo. As grandes diferenças verificadas entre os dois anos no acúmulo de massa seca e nas taxas de crescimento inicial da cultura corroboram esta hipótese (Tabela 1).

Os maiores valores médios de área foliar, IAF e TCC externados pelo híbrido AS3601 no início do ciclo em 1998/99 não promoveram incrementos significativos no rendimento de grãos deste material, em relação aos demais híbridos utilizados no trabalho (Tabelas $1 \mathrm{e}$ 2). Da mesma forma, a menor produção de fitomassa manifestada pelo híbrido C909 no segundo ano agrícola não impôs restrições significativas na sua produtividade (Tabelas 1 e 2). A análise de correlação também não identificou uma associação positiva significativa entre as variáveis de crescimento inicial e o rendimento de grãos e seus componentes (Tabela 3), com exceção da área foliar e IAF em 1999/00. Todos estes dados contrariam uma das hipóteses do trabalho, a qual inferia que um desenvolvimento mais rápido da cultura do milho logo após a emergência lhe traria maior eficiência de uso da radiação solar e incrementos na produtividade.

O híbrido AS 3466 apresentou maior rendimento biológico do que as demais cultivares em 1999/2000 (Tabela 2). Houve correlação significativa entre o rendimento biológico, a produção de massa seca no início do ciclo e a TCC (Tabela 3). Isto ressalta a associação existente entre a capacidade da cultura de investir na produção de massa seca até o estágio de
Tabela 2 - Rendimento de grãos, número de espigas por planta, massa de mil grãos (MMG), número de grãos por espiga de híbridos de milho. Faculdade de Agronomia, Lages, SC.

\begin{tabular}{|c|c|c|c|c|c|c|}
\hline \multicolumn{7}{|c|}{ Estação de crescimento 1998/99 } \\
\hline Cultivares & $\begin{array}{c}\text { Rendimento } \\
(\mathrm{kg} / \mathrm{ha})\end{array}$ & $\mathrm{N}^{0}$ esp./planta & \multicolumn{2}{|c|}{ MMG (g) } & \multicolumn{2}{|c|}{$\mathrm{N}^{0}$ gr/espiga } \\
\hline Cargill 901 & $7.911 \mathrm{~ns}$ & $0,95 \mathrm{~ns}$ & \multicolumn{2}{|c|}{$332,7 \mathrm{a}^{*}$} & \multicolumn{2}{|c|}{$365,0 \mathrm{~b}^{*}$} \\
\hline AS 3601 & 8.652 & 0,95 & \multicolumn{2}{|c|}{$315,2 \mathrm{~b}$} & \multicolumn{2}{|c|}{419,8 a } \\
\hline Cargill 505 & 7.193 & 1,01 & \multicolumn{2}{|c|}{332,4 a } & \multicolumn{2}{|l|}{$368,8 \mathrm{~b}$} \\
\hline AS 32 & 7.569 & 1,01 & \multicolumn{2}{|c|}{$298,0 \mathrm{c}$} & \multicolumn{2}{|l|}{$358,8 \mathrm{~b}$} \\
\hline AS 3466 & 8.394 & 0,96 & \multicolumn{2}{|c|}{$324,8 \mathrm{ab}$} & \multicolumn{2}{|l|}{$367,5 \mathrm{~b}$} \\
\hline \multicolumn{7}{|c|}{ Estação de crescimento 1999/00 } \\
\hline & $\begin{array}{l}\text { Rendimento } \\
\text { (kg/ha) }\end{array}$ & $\mathrm{N}^{0}$ esp./planta & MMG (g) & $\mathrm{N}^{0}$ gr/espiga & $\begin{array}{c}\text { Rendimento } \\
\text { Biológico }\end{array}$ & IC (\%) \\
\hline Cargill 909 & $10.608 \mathrm{~ns}$ & $1,08 \mathrm{~ns}$ & $344,8 \mathrm{~b}^{*}$ & $470,4 \mathrm{~ns}$ & $1198,5 \mathrm{~b}^{*}$ & $50,6 \mathrm{a}^{*}$ \\
\hline AS 3601 & 9.933 & 1,09 & $330,5 \mathrm{~b}$ & 442,2 & $1183,0 \mathrm{~b}$ & $47,8 \mathrm{ab}$ \\
\hline Dina 500 & 9.881 & 1,03 & $363,5 \mathrm{a}$ & 427,9 & $1196,8 \mathrm{~b}$ & $49,3 \mathrm{ab}$ \\
\hline AS 32 & 9.736 & 1,08 & $307,5 \mathrm{c}$ & 465,7 & $1212,8 \mathrm{~b}$ & 46,8 bc \\
\hline AS 3466 & 9.474 & 1,03 & $340,5 \mathrm{~b}$ & 418,6 & $1475,3 \mathrm{a}$ & $44,3 \mathrm{c}$ \\
\hline
\end{tabular}

* médias não seguidas pela mesma letra na coluna diferem estatisticamente pelo teste de Duncan, a $5 \%$ de significância de erro.

ns = não significativo a $5 \%$, nas comparações na coluna. 
Tabela 3 - Análise de correlação linear entre rendimento de grãos, componentes de rendimento e as variáveis de crescimento inicial. Faculdade de Agronomia, Lages, SC.

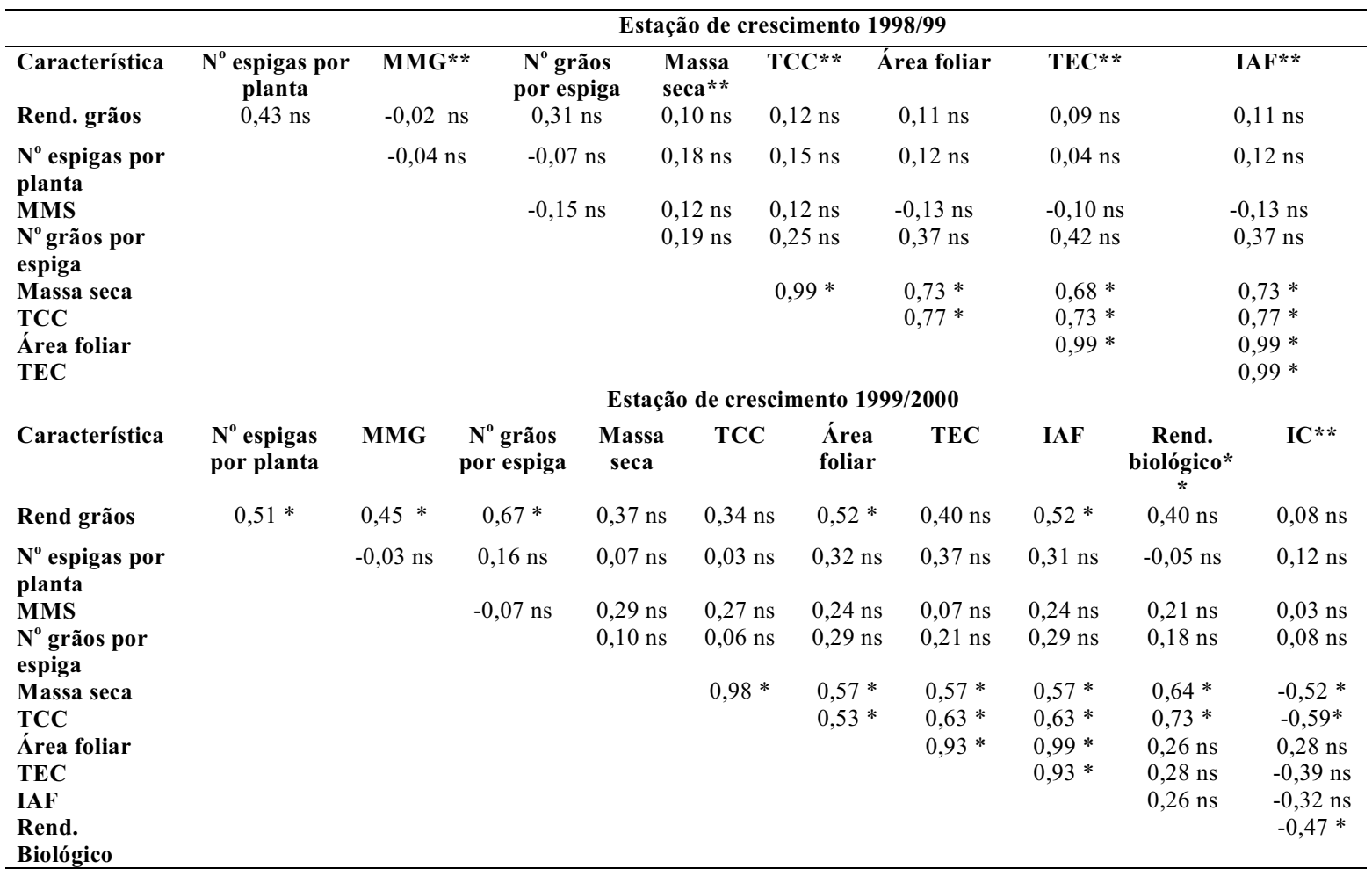

* Correlação significativa a 5\% de probabilidade de erro. ns - correlação não significativa.

** Massa de mil grãos (MMG), Massa seca (MS) da parte aérea (folhas + colmo), taxa de crescimento celular (TCC), taxa de expansão celular (TEC), índice de área foliar (IAF), índice de colheita (IC).

dez folhas expandidas e a fitomassa total no final do ciclo. Contudo, o rendimento de grãos por hectare depende também da capacidade das culturas de alocar fotoassimilados à estrutura de interesse econômico (SANGOI et al., 1997; ALMEIDA et al., 1998). Neste aspecto, o híbrido AS 3466 apresentou os menores valores de índice de colheita, enquanto que o híbrido C 909 concentrou mais de $50 \%$ da massa seca total nos grãos (Tabela 2).

Houve correlação positiva entre as cinco variáveis utilizadas para estimar o crescimento inicial (MS, área foliar, TEC, IAF e TCC) nos dois anos de realização do trabalho (Tabela 3 ). Portanto, pode-se afirmar que as plantas que apresentaram maior massa seca nas primeiras semanas após a emergência também expressaram maior área foliar e IAF. Isto ocorreu porque no início do ciclo do milho a planta investe seus fotoassimilados prioritariamente na diferenciação de folhas (RITCHIE \& HANWAY, 1993; FANCELLI \& DOURADO-NETO, 2000). Conseqüentemente, a maior parte da massa seca produzida se traduz em incremento de área foliar. A correlação significativa verificada entre os parâmetros utilizados para avaliar o crescimento inicial indica que tanto análises destrutivas, tais como aquelas ligadas ao acúmulo de massa seca da planta, quanto as não destrutivas, relacionadas à estimativa de área foliar, podem ser utilizadas indistintamente, de acordo com a sua conveniência, para caracterizar o crescimento inicial da cultura do milho.

A pequena associação entre a velocidade de crescimento inicial e o rendimento de grãos confirmou as observações feitas por TOLLENAAR et al. (1991), McCULLOUGH et al. (1994) e TOLLENAAR \& WU (1999), segundo as quais os ganhos em produtividade que os híbridos contemporâneos apresentam, em relação aos genótipos utilizados em décadas passadas, não estão relacionados ao maior acúmulo de massa seca e expansão foliar até o estádio de 12 folhas expandidas.

A definição do rendimento de grãos e de seus componentes é um processo seqüencial que envolve um perfeito sincronismo entre as diferentes etapas fenológicas do ciclo da cultura. Segundo GARDNER et al. (1985) e WESTGATE et al. (1997), o rápido crescimento inicial é uma característica importante dentro deste contexto em regiões de alta

Ciência Rural, v. 33, n. 2, mar-abr, 2003. 
latitude, nas quais a duração da estação de crescimento é reduzida. Nestes casos, cultivares que externem rápido desenvolvimento de área foliar interceptam e utilizam a radiação solar de forma mais efetiva, convertendo isto em maiores produtividades. Por outro lado, em regiões subtropicais e tropicais, como a que se conduziu o presente trabalho, a velocidade de crescimento inicial demonstrou não ter vinculação direta com a produtividade dos híbridos testados, possivelmente porque a cultura teve tempo suficiente para compensar as diferenças existentes nas fases iniciais em etapas subsequentes do ciclo da cultura.

\section{CONCLUSÕES}

As variáveis utilizadas para estimar o crescimento inicial (MS, área foliar, TEC, IAF e TCC) se correlacionam positivamente.

A maior velocidade de crescimento inicial de híbridos de milho não proporciona incremento no rendimento de grãos.

\section{REFERÊNCIAS BIBLIOGRÁFICAS}

ALMEIDA, M.L.de; MUNDSTOCK, C.M.; SANGOI, L. Conceito de ideotipo e seu uso no aumento do rendimento potencial de cereais. Ciência Rural, Santa Maria, v.28, n.2, p.325-332, 1998.

AUSTIN, R.B. et al. Genetic improvements in winter wheat yields since 1900 and associated physiological changes. Journal of Agricultural Science, Cambridge, v.94, p.675-690, 1980.

BOUKERROU, L.; RASMUSSON, D.C. Breeding for high biomass yield in spring barley. Crop Science, Madison, v.30, p.31-35, 1990.

CAUSSE, M. et al. Sucrose phophate synthase: an enzyme with heterotic activity correlated with maize growth. Crop Science, Madison, v.35, p.995-1011, 1995.

COMISSÃO DE FERTILIDADE DO SOLO-RS/SC. Recomendações de adubação e calagem para os estados do Rio Grande do Sul e Santa Catarina. Passo Fundo : SBCS-Núcleo Regional Sul, EMBRAPA/CNPT, 1995. 223p.

COX, T.S. et al. Genetic improvement of agronomic traits of hard red winter wheat cultivars from 1919 to 1987. Crop Science, Madison, v.28, n.3, p.756-760, 1988.

CREGAN, P.B.; YAKLICH, R.W. Dry matter and nitrogen accumulation and partitioning in selected soubean genotypes of difference derivation. Theor Appl Genet, v.72, p.782786, 1986.

EMBRAPA-CENTRO NACIONAL DE PESQUISA DE SOLOS. Sistema brasileiro de classificação de solos. Rio de Janeiro : Embrapa, 1999. 412p.
FANCELLI, A.L. Fisiologia da produção e aspectos básicos de manejo para alto rendimento. In: SANDINI, I.; FANCELLI, A.L. (Eds). In:__ Milho: estratégias de manejo para a região sul. Guarapuava : Fundação Agrária de Pesquisa Agropecuária, 2000. Cap.7, p.103-116.

FANCELli, A.L.; DOURAdO NETO, D. Produção de milho. Guaíba : Agropecuária, 2000. 360p.

GARDNER, F.P.; PEARCE, R.B.; MITCHELL, R.L. Physiology of crop plants. Ames : Iowa State University, 1985. 327p.

LOOMIS, R.J.; AMTHOR, J.S. Yield potential, plant assimilatory capacity and metabolic efficiencies. Crop Science, Madison, v.39, n.6, p.1584-1596.

MEROTTO Jr., A. et al. A desuniformidade de emergência reduz o rendimento de grãos do milho, principalmente em alta população de plantas. Ciência Rural, Santa Maria, v.29, n.4, p.595-601, 1999.

MCCULLOUGH, D.E.. et al. Influence of $\mathrm{N}$ supply on the development and dry matter accumulation of an old and a new maize hybrid. Canadian Journal of Plant Science, Ottawa, v.74, n.2, p.471-478, 1994.

RITCHIE, S.W.; HANWAY, J.J. How a corn plant develops. Ames : Iowa State University of Science and Technology, 1992. 26p. (Special Report, 48).

ROCHER, J.P. et al. Genetic variability in carbon fixation, sucrose-P-synthase and ADP glucose pyrophosphorylase in maize plants of differing growth rate. Plant Physiology, Lancaster, v.89, n.2, p.416-420, 1989.

ROOD, S.B. et al. Gibberellins and heterosis in maize quantitative relationships. Crop Science, Madison, v.30, n.1, p.281-286, 1990 .

SANGOI, L.; ALMEIDA, M.L. de; ENDER, M. Advantages and limitations of using ideotypes to bred crop plants. Pesquisa Agropecuária Gaúcha, Porto Alegre, v.3, n.1, p.73 - 80, 1997.

STEWART, D.W.; DWYER, L.M. Appearance time, expansion rate and expansion duration for leaves of field-grown maize (Zea mays L.). Canadian Journal of Plant Science, Ottawa, v.74, n.1, p.31-36, 1994.

TOLLENAAR, M. Physiological basis of genetic improvement of maize hybrids in Ontario from 1959 to 1988. Crop Science, Madison, v.31, n.1, p.119-124, 1991.

TOLLENAAR, M.; MIHAJlOVIC, M.; AGUILERA. Temperature response of dry matter accumulation, leaf photosynthesis, and chlorophyll fluorescence in an old and new maize hybrid during early development. Canadian Journal of Plant Science, Ottawa, v. 71, n. 2, p.353-359, 1991.

TOLLENAAR, M.; WU, J. Yield improvement in temperate maize is attributable to greater stress tolerance. Crop Science, Madison, v. 39, n.6, p.1597-1604, 1999.

WESTGATE, M.E. et al. Rapid canopy closure for maize production in the northern US corn belt: Radiation-use efficiency and grain yield. Field Crops Research, Amsterdam, v.49, n.2, p.249-258, 1997. 